\title{
El Modelo de Valuación Inmobiliaria en México.
}

The Pricing Model Real Estate in Mexico

José Manuel Salas Tafoya

Universidad de Guadalajara

salastafoya@gmail.com

\section{Resumen}

Valuación es la acción o efecto de valuar, a su vez, significa valorar, entendido como el reconocimiento o apreciación del valor de algo. Existen diferentes tipos de valuación, entre otras, la inmobiliaria, que determina el valor de un inmueble mediante el análisis de los elementos tangibles e intangibles. Sin embargo, la determinación de valor de un inmueble tradicionalmente se obtiene a partir del valor de cambio, donde la concepción transaccional-adquisitivo y psicológica-hedonista junto con la escasez se erigen como elementos determinantes. En tal sentido, la valuación inmobiliaria se sustenta en la insuficiencia del bien y esta en elemento determinante en la oferta y la demanda.

En México la Sociedad Hipotecaria Federal y el INDAABIN norman los servicios de valuación. La primera para bienes de propiedad privada, la segunda para bienes de la nación. Las reglas de ambas instancias se caracterizan por impulsar el proceso mediante la aplicación de los enfoques de: mercado, físico o residual. Además, por el tipo de documentación solicitada, la cual se orienta a la posesión legal del inmueble.

Por consiguiente podemos establecer que el proceso de valuación inmobiliaria en México privilegia el enfoque comparativo de mercado, donde el valor de los inmuebles se determina de acuerdo a la relación entre la demanda que existe de un bien en el mercado y la cantidad del mismo que es ofrecida. Por consiguiente, la valuación inmobiliaria presenta una importante lejanía respecto a la conceptualización del término y debilidad analítica respecto fenómenos multidisciplinares. 
Palabras clave: Valuación, valuación inmobiliaria, escasez

\section{Abstract}

Valuation is the action or effect of valuing, in turn, means valuing, understood this as the recognition or appreciation of the value of something. There are different types of valuation, among others, real estate, which determines the value of a property by analyzing the tangible and intangible elements. However, determining the value of a property it is typically obtained from the value of the exchange rate, where the transactional-purchasing and psychological-hedonistic conception with shortages stands as determinants elements. In this case, the real estate valuation is based on the insufficiency of the well and is a determining element in the supply and demand.

In Mexico the Federal Mortgage Society and INDAABIN rule valuation services. The first one to private property and the second one for wells of the nation. The rules of both instances are characterized by impulse the process by applying approaches of: market, physical or residual. In addition, the type of requested documentation, which is oriented to the legal possession of the property

Therefore we can state that the process of real estate valuation in Mexico favors comparative market approach, where the value of property is determined according to the relationship between the demand that exists of a well in the market and the amount thereof which is offered. Therefore, the real estate valuation presents an important remoteness to the conceptualization of the term and analytical weaknesses regarding multidisciplinary phenomena.

Key words: Valuation, property valuation, shortages.

Fecha Recepción: Diciembre 2014 Fecha Aceptación: Enero 2015 


\section{Introducción}

\section{Valuación de bienes}

'Valuación' es un término utilizado en similitud retórica con tasación y valoración. La Real Academia de la Lengua Española (RAE: 2012) la define como la acción y efecto de valorar y, valorar es reconocer, estimar o apreciar el valor o mérito de alguien o algo. Respecto a tasación la RAE la define como la estimación del valor de un bien o de un servicio. En referencia a valuación menciona que es la acción o efecto de valuar. Habida cuenta de que valuar significa valorar. En este sentido, la tríada de términos guarda una estrecha vinculación entre sí, donde el punto de similitud es la referencia al concepto valor, determinado éste mediante un avalúo ${ }^{1}$.

A nivel institucional el Instituto de Administración y Avalúos de Bienes Nacionales $(\text { INDAABIN })^{2}$ define la valuación como “el procedimiento técnico y metodológico que, mediante la investigación física, económica, social, jurídica y de mercado, permite estimar el monto, expresado en términos monetarios, de las variables cuantitativas y cualitativas que inciden en el valor de cualquier bien”. En el mismo ámbito el Congreso del Estado de Jalisco (1998) declara que valuación "es un proceso que tiene como objetivo estimar el valor de un bien mediante un avalúo que determina la medida de valor en unidades monetarias"3.

Como se observa, en valuación coexisten dos términos interrelacionados pero independientes a la vez, uno es el valor de los bienes, el otro es el precio de los bienes. El International Valuation Standards Council ${ }^{4}$ (IVSC: 2010), en las Normas Internacionales de Valoración establece que valor no es un hecho sino una estimación del precio probable a pagar por bienes y servicios en un intercambio o una medida de los beneficios económicos de ser propietario de esos bienes o servicios. En cambio, precio es un término que hace referencia al importe solicitado, ofrecido o pagado por un bien o servicio.

En nuestro país los servicios de valuación están reglados por la Secretaría de Economía mediante la norma mexicana NMX-C-459-SCFI-ONNCCE-2007 ${ }^{5}$. En ella se establecen siete categorías de bienes: empresas, intangibles, muebles, inmuebles, agropecuarios o rurales, obras de arte y de alhajas y joyería. La valuación de negocios — como se menciona en la declaratoria- se considera materia distinta a esta norma. 
Acerca de los alcances de la valuación inmobiliaria Jerónimo Aznar (2005:10) señala, ésta tiene el objetivo de:

determinar el valor de un bien, teniendo en cuenta, los elementos de comparación, características o variables explicativas que lo caracterizan, el entorno económico-temporal en que se encuentra, mediante la utilización de un método contrastado de cálculo aplicado por un tasador profesional y que permita al experto incorporar tanto el conocimiento objetivo como el subjetivo.

En cuanto al poseedor/propietario, los bienes pueden ser de carácter público o privado. Los primeros corresponden a los bienes nacionales ${ }^{6}$, los segundos a los bienes de propiedad particular. La regulación en materia de valuación de bienes inmuebles de propiedad nacional corresponde al INDAABIN, mientras, para los bienes inmuebles de propiedad particular a la Sociedad Hipotecaria $\mathrm{Federal}^{7}$, a través de las "Reglas de carácter general que establecen la metodología para la valuación"»8 las cuales deberán observarse en los avalúos.

Los antecedentes de la valuación de bienes inmuebles ${ }^{9}$ en México remiten al inicio del siglo pasado cuando aparece de manera formal, "exclusivamente con fines tributarios del impuesto predial, que fue cuando se establecieron las bases para el Catastro de la Ciudad de México" (Sánchez: 1986). El objetivo era describir el bien inmueble y asignar impuesto sobre la propiedad, en alusión a la obligación constitucional hacia los mexicanos de contribuir en los gastos públicos.

En el ámbito de la bibliografía acerca de la valuación inmobiliaria, esta se ha especializado en dos tipos principalmente, por un lado avalúos de activos (tema que nos ocupa en el presente capítulo) y, por el otro, avalúos con objetivo catastral. Esto significa que la literatura acerca de la valuación de bienes inmuebles se orienta casi de manera exclusiva al análisis de los bienes inmuebles y, en consecuencia, a la identificación de componentes de tipo objetivo, a su vez, de carácter endógeno. Asimismo, a la resolución de ejercicios a través de los métodos tradicionales de valuación establecidos por las instituciones gubernamentales reguladoras de los servicios de valuación, como son, el método físico o directo, el método de capitalización de rentas y el método comparativo de mercado. 
De acuerdo a las ideas anteriores podemos establecer que la valuación inmobiliaria es un proceso técnico metodológico cuyo objetivo es determinar el valor del bien inmueble mediante la medición de componentes físicos, económicos, sociales, jurídicos y de mercado, propios del bien y el enclave del mismo.

\section{Enfoques y técnicas para la valuación inmobiliaria en México}

La valuación inmobiliaria es un proceso establecido y reglado. A nivel internacional, el International Valuation Standards Council (IVSC) es una entidad empresarial que se han encargado de plantear criterios de valuación con carácter global y, la compatibilidad entre las normas globales con las regionales y locales. Habida cuenta de existir discordancia entre unas y otras buscan la adhesión de las inferiores o de menor alcance territorial.

A nivel nacional, la Secretaría de Economía ${ }^{10}$, organismo del gobierno federal mexicano es la encargada de normar la valuación por conducto de la Dirección General de Normas mediante la declaratoria de vigencia de la norma mexicana NMX-C-459-SCFI-ONNCCE-2007 Servicios de Valuación, la cual establece los requisitos generales que deben cumplirse a fin de proporcionar la confianza de que el servicio de valuación sea otorgado con la competencia técnica, imparcialidad, confidencialidad y esmero que el cliente merece, mediante:

1. Documentación e información que permitan el inicio del proceso de valuación.

2. Inspección de los bienes a valuar para constatar su existencia, identificación y ubicación.

3. Aplicación de los enfoques de valuación ${ }^{11}$, debiendo especificar y justificar cuando alguno de ellos no sea aplicable.

4. Informe de valuación conforme con los enfoques y principios ${ }^{12}$ expresados en la norma.

5. Informe de valuación y el soporte documental utilizado durante un lapso mínimo de un año o, en su caso, por el periodo que establezcan los ordenamientos legales aplicables. En el caso de las personas morales, también deben guardar una copia del informe de valuación por el periodo aquí establecido. 
6. Participación de algún otro valuador o experto en algún tema específico necesario para llevar a cabo el proceso de valuación, otorgándole el crédito correspondiente.

La valuación de bienes inmuebles de propiedad nacional — como se mencionó anteriormenteestá normada por el INDAABIN mediante la ordenación del proceso valuatorio (véase tabla $\mathrm{N}^{\circ}$ 1) y por la Secretaría de Hacienda y Crédito Público (SHCP) a través de la Norma Específica de Información Financiera Gubernamental (NEIFG 003-Bienes Nacionales). Para el caso de bienes inmuebles de propiedad particular corresponde a la SHF a través de las "Reglas metodológicas para la valuación de inmuebles" (véase tabla $\mathrm{N}^{\circ}$ 2).

Es importante destacar parte del contenido del código de ética del proceso valuatorio de bienes nacionales que plantea el INDAABIN (2015), pues implica el alcance de la valuación y la consideración de distintos componentes:

Transparencia

Los avalúos incluirán una descripción clara y exacta del alcance de la asignación, la definición de valor empleada y el uso que se le va a dar al trabajo, mencionando todas las suposiciones, escenarios hipotéticos o condiciones limitantes que afecten directamente a la valuación, y en aquellos casos en que esto sea apropiado, indicando el posible efecto sobre el valor. Se deberán evitar conflictos de intereses entre los clientes, usuarios de los trabajos valuatorios, Peritos Valuadores y el personal del INDAABIN, así como con sus familias, empresas, parientes, amigos o asociados. 
Tabla No 1

Proceso valuatorio INDAABIN

\begin{tabular}{|c|c|c|}
\hline $\mathbf{N}^{\circ}$ & Etapa & Actividad \\
\hline 1 & $\begin{array}{l}\text { Recepción de } \\
\text { solicitud y base } \\
\text { informativa }\end{array}$ & $\begin{array}{l}\text { Revisión de: } \\
\text { - Plano de ubicación del bien } \\
\text { - Plano topográfico del terreno con superficie, medidas y } \\
\text { colindancias de la poligonal envolvente } \\
\text { - Larguillo completo del cadenamiento que indique origen y } \\
\text { destino } \\
\text { - Escrituras } \\
\text { - Constancia de uso del suelo } \\
\text { - Planos arquitectónicos aprobados por la autoridad } \\
\text { - } \text { Informe de costos anuales de operación del inmueble } \\
\text { - Listado de bienes distintos a la tierra y de máquinas o } \\
\text { - equipos anexos a las construcciones afectadas } \\
\text { Dictamen de seguridad estructural. }\end{array}$ \\
\hline 2 & $\begin{array}{l}\text { Identificación } \\
\text { del bien a } \\
\text { valuar }\end{array}$ & $\begin{array}{l}\text { - Analizar la solicitud del promovente que pide el trabajo } \\
\text { valuatorio para identificar el bien a valuar y confirmar el } \\
\text { criterio técnico que resulte procedente. } \\
\text { - Revisar la documentación procedente que el caso requiere. } \\
\text { - Establecer el uso, propósito y finalidad del avalúo, así como } \\
\text { la fecha de valores. } \\
\text { - Especificar y describir el alcance de la valuación, } \\
\text { incluyendo primordialmente los bienes a valuar. } \\
\text { - Concertar cita con el funcionario autorizado por el } \\
\text { promovente, para la inspección física del bien por valuar. }\end{array}$ \\
\hline
\end{tabular}




\begin{tabular}{|c|c|c|}
\hline 3 & $\begin{array}{l}\text { Inspección } \\
\text { del bien a } \\
\text { valuar }\end{array}$ & $\begin{array}{l}\text { La investigación de cada uno de los elementos que } \\
\text { conforman el bien, debe realizarse independientemente, } \\
\text { para que se pueda tener un análisis objetivo de cada uno } \\
\text { de los precios que van a incidir en los indicadores de valor } \\
\text { de los enfoques empleados en la realización del avalúo. }\end{array}$ \\
\hline 4 & $\begin{array}{l}\text { Recopilación } \\
\text { de } \\
\text { información }\end{array}$ & $\begin{array}{l}\text { La investigación de mercado para la estimación del valor de } \\
\text { un terreno, debe contener elementos de la misma vecindad } \\
\text { inmediata o mediata, como pueden ser: ubicación, zona, } \\
\text { uso del suelo autorizado o potencial, superficie, forma, } \\
\text { topografía, entre otros. }\end{array}$ \\
\hline 5 & $\begin{array}{l}\text { Selección del } \\
\text { procedimiento } \\
\text { técnico: } \\
\text { - Enfoque de: } \\
\text { Costos } \\
\text { ingresos } \\
\text { De mercado }\end{array}$ & $\begin{array}{l}\text { El valor de los inmuebles, en cada caso debe ser } \\
\text { dictaminado de acuerdo con los procedimientos técnicos } \\
\text { que le apliquen. }\end{array}$ \\
\hline 6 & $\begin{array}{l}\text { Cálculo de } \\
\text { indicadores de } \\
\text { valor }\end{array}$ & $\begin{array}{l}\text { - El cálculo de valor conclusivo de los inmuebles para su } \\
\text { adquisición, es mediante la aplicación de enfoques } \\
\text { comparativo de mercado, de costos, y de ingresos, así } \\
\text { como de otros parámetros valuatorios que procedan, de } \\
\text { acuerdo con los procedimientos técnicos correspondientes } \\
\text { a bienes inmuebles, utilizando según sea el caso. } \\
\text { - De los indicadores de valor obtenidos según los distintos } \\
\text { enfoques aplicables en cada procedimiento técnico, es } \\
\text { importante aplicar una ponderación, esto es multiplicar cada } \\
\text { uno de los indicadores de valor obtenidos de cada enfoque } \\
\text { por el porcentaje de ponderación que determine el valuador } \\
\text { de bienes nacionales según el uso y el propósito del avalúo. }\end{array}$ \\
\hline
\end{tabular}




\begin{tabular}{|c|c|c|c|}
\hline 7 & $\begin{array}{l}\text { Ponderación y } \\
\text { obtención del } \\
\text { valor conclusivo }\end{array}$ & $\begin{array}{l}\text { - El valuador de bienes nacionales deberá basarse en el } \\
\text { resultado de la ponderación para estimar el valor con el que } \\
\text { se debe concluir su estimación. }\end{array}$ \\
\hline 8 & $\begin{array}{l}\text { Elaboración } \\
\text { del trabajo y } \\
\text { dictamen } \\
\text { valuatorio }\end{array}$ & $\begin{array}{l}\text { - Debe ser redactado en una forma descriptiva y clara, } \\
\text { considerando que va dirigido a servidores públicos o } \\
\text { personas que no necesariamente conocen de avalúos. }\end{array}$ \\
\hline
\end{tabular}

Fuente: INDAABIN.

La SHCP emitió la NEIFG 003 - Bienes Nacionales, la cual tiene como objetivo establecer las bases para el registro contable y la valoración de los bienes nacionales que deben ser aplicados por las Administradoras y las áreas centrales de contabilidad, con el propósito de generar información actualizada sobre la integración del Patrimonio Nacional que permita elaborar el inventario de éste; así como lo correspondiente para conocer el estado que guarda, derivado de su uso, aprovechamiento, explotación y administración; promover su conservación, mantenimiento, vigilancia y salvaguarda, conforme al esquema siguiente.

Los bienes muebles e inmuebles a los que se refiere la anterior norma son los identificados como: históricos, artísticos y culturales, por ejemplo, parroquias, monumentos, bibliotecas, etc.; arqueológicos, como son, monumentos arqueológicos, pinturas, etc.; y de uso, tales como, escuelas, carreteras, espacio aéreo, etc.

Para la valoración de los bienes muebles e inmuebles en caso de daños parciales o totales, la norma establece que se deberá reflejar el valor de reposición con el propósito de llevar a cabo las acciones de su resarcimiento o recuperación por las responsabilidades correspondientes. Y en el caso de la valoración de bienes enajenables, el INDAABIN establecerá un valor determinado, mismo que no podrá ser mayor al de mercado. Para el caso de bienes inmuebles el INDAABIN señalará el valor de éstos. Es importante destacar que el INDAABIN ofrece avalúos paramétricos ${ }^{13}$ a las dependencias y entidades de la Administración Pública Federal y otras instituciones públicas, los cuales tienen como objeto el registro de valores de sus bienes inmuebles (SHCP: 2013), con base a precios unitarios determinados mediante parámetros de 
valor de terreno y de construcciones, de acuerdo a sus características físicas y/o calidad, así como su uso o tipo constructivo, considerando deméritos en los casos que aplique

\section{Tabla $\mathrm{N}^{\circ} 2$}

Reglas metodológicas para la valuación de inmuebles

\begin{tabular}{|c|c|c|c|}
\hline $\begin{array}{l}\text { Tipo de } \\
\text { inmueble }\end{array}$ & $\begin{array}{l}\text { Tipo de } \\
\text { valor }\end{array}$ & $\begin{array}{l}\text { Enfoques por } \\
\text { estudiar }\end{array}$ & $\begin{array}{l}\text { Documentación necesaria en } \\
\text { copia simple }\end{array}$ \\
\hline $\begin{array}{l}\text { Terreno para } \\
\text { desarrollo } \\
\text { habitacional }\end{array}$ & $\begin{array}{l}\text { - Valor } \\
\text { comercial }\end{array}$ & $\begin{array}{l}\text { - Mercado } \\
\text { - Físico } \\
\text { • Estudio } \\
\text { residual }\end{array}$ & $\begin{array}{l}\text { - Escritura de propiedad } \\
\text { - Boleta predial de catastro } \\
\text { - Boleta de agua, en su caso } \\
\text { - Identificación de la poligonal del } \\
\text { terreno mediante croquis } \\
\text { - Licencia de construcción } \\
\text { - Factibilidad de servicios } \\
\text { expedida por el municipio } \\
\text { - Planos arquitectónicos } \\
\text { - Especificaciones de obra } \\
\text { - Presupuestos y calendario obra } \\
\text { - Programa de ventas }\end{array}$ \\
\hline $\begin{array}{l}\text { Individualización } \\
\text { de crédito } \\
\text { hipotecario } \\
\text { para vivienda } \\
\text { terminada }\end{array}$ & $\begin{array}{l}\text { - Valor } \\
\text { comercial }\end{array}$ & $\begin{array}{l}\text { - Mercado } \\
\text { - Físico } \\
\text { - Capitalización } \\
\text { de rentas, } \\
\text { en su caso }\end{array}$ & $\begin{array}{l}\text { - Planos arquitectónicos } \\
\text { - Boleta predial } \\
\text { - Boleta de agua } \\
\text { - Oficio de terminación de obra, } \\
\text { para vivienda nueva }\end{array}$ \\
\hline $\begin{array}{l}\text { Recuperación } \\
\text { de crédito }\end{array}$ & $\begin{array}{l}\text { - Valor } \\
\text { comercial } \\
\text { - Valor de } \\
\text { reposición }\end{array}$ & $\begin{array}{l}\text { - Mercado } \\
\text { - Físico } \\
\text { - Capitalización } \\
\text { de rentas }\end{array}$ & $\begin{array}{l}\text { - Escritura de propiedad } \\
\text { - Boleta predial } \\
\text { - Boleta de agua, en su caso } \\
\text { - Planos arquitectónicos }\end{array}$ \\
\hline
\end{tabular}




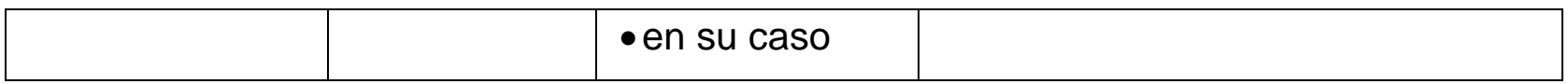

Fuente: Sociedad Hipotecaria Nacional

En referencia al procedimiento técnico para la elaboración de avalúos, el INDAABIN establece la utilización de los enfoques de: costos, ingresos y mercado. Por su parte, la SHF determina los enfoques: comparativo o de mercado, físico o de costos, residual y capitalización de rentas.

\section{Enfoque comparativo o de mercado (INDAABIN).}

Este enfoque involucra la recopilación de información pertinente del mercado de bienes comparables al bien por valuar, tratando de conocer los valores de operaciones cerradas y analizando la oferta y la demanda, para poder llegar a un indicador que permita establecer el precio más probable de compra para dicho bien.

Se basa igualmente en los principios de: Sustitución, de la Oferta y la Demanda, de Homogeneidad o Conformidad, de Cambio, de Progresión y Regresión, de Crecimiento, Equilibrio y Declinación, de Competencia y de Mayor y Mejor Uso.

\section{Enfoque físico o de costos (INDAABIN).}

Se basa primeramente en la estimación del costo de reproducción o de reposición de un bien igual o de características semejantes al bien analizado a la fecha del avalúo. Al resultado de esta estimación se le denomina Valor de Reposición Nuevo (VRN). Si el bien no es nuevo, su valor se afectará por los diversos factores de depreciación y obsolescencia aplicables, según sea el caso, y así se obtiene el Valor Físico también llamado Valor Neto de Reposición. (VNR).

Se fundamenta en los Principios de Sustitución, de Mayor y Mejor Uso, De la Oferta y la Demanda, de Crecimiento, Equilibrio y Declinación, de Contribución y de Productividad Excedente.

En el caso de inmuebles, es un método híbrido debido a que conjunta el valor del terreno con los costos de reposición o reproducción de las construcciones y mejoras como son: edificios, instalaciones especiales, obras complementarias y elementos accesorios. 
Establece que el valor de un bien inmueble o mueble es comparable al costo de reposición o reproducción de uno igualmente deseable y con utilidad o funcionalidad semejante a aquél que se valúa, considerando todas aquellas condiciones que pueden influir en el valor de cada uno de los bienes.

El uso de este enfoque, en ocasiones tiene como propósito conocer el valor de bienes, atípicos que no tienen comparables de operaciones realizadas en el mercado en estudio, o en su defecto, de los que no hay ofertas de mercado.

\section{Enfoque de capitalización de rentas (INDAABIN).}

Este enfoque, basado en los Principios de Anticipación, de Competencia, de Mejor y Mayor Uso, de la Oferta y de la Demanda, de Equilibrio, de Contribución y de Productividad Excedente, se aplica a los bienes susceptibles de una explotación económica, cuyas expectativas de ingresos, que previsiblemente proporcionarán en el futuro, sustentan el valor del bien.

Este enfoque considera el valor presente de los beneficios futuros, derivados del bien por valuar y es medido a través de la capitalización de los ingresos. A este valor presente se le conoce como valor de capitalización.

Valor de capitalización.- Es el indicador de valor de un bien, estimado en función de la capacidad productiva financiera del bien.

Capitalización directa de ingreso anual.- También conocida como capitalización "a perpetuidad", es un método utilizado para convertir una estimación del ingreso esperado durante un año, en un indicador del valor en un solo paso ya sea dividiendo el ingreso estimado entre una tasa de capitalización de ingresos.

El valor que se obtiene al aplicar la capitalización directa del monto de una renta, se le denomina generalmente como Valor de Capitalización de Rentas (tratándose de inmuebles).

\section{Enfoque residual (INDAABIN).}

El valor residual es el que resulta del análisis de los beneficios y de los costos para un inversionista que adquiere un terreno urbano en breña o con construcciones, para 
desarrollar en él un proyecto inmobiliario de aprovechamiento del mismo; el método residual se aplica siempre y cuando no existan evidencias adecuadas y confiables de mercado, y exista viabilidad técnica, jurídica, social, económica y financiera del proyecto inmobiliario, considerando el mayor y mejor uso del inmueble.

Dependiendo de la naturaleza e importancia del inmueble por valuar, así como de la complejidad del caso, el método residual podrá llevarse a cabo mediante dos análisis:

a) Residual estático ${ }^{14}$.

b) Residual dinámico ${ }^{15}$.

Por consiguiente, podemos establecer que el actual proceso de valuación inmobiliaria en México, normado por las instancias gubernamentales reguladoras de los servicios de valuación está fundamentado en enfoques tradicionales como son el comparativo o de mercado, el físico o de costos, el de capitalización de rentas y el residual. Los cuales a su vez, enfatizan los elementos endógenos, tangibles y edificatorios de los bienes.

\section{Sustento teórico económico de la valuación inmobiliaria}

El proceso histórico de la economía ha transitado esencialmente bajo el abrigo de dos grandes corrientes teóricas. La primera nace durante la segunda mitad del siglo XVIII con la aparición de los fisiócratas franceses, quienes por un lado atribuían a la naturaleza el origen de la riqueza y, por el otro, concebían la plusvalía como un incremento material de los valores de uso, y no como un incremento del valor. Sostenían además que el buen funcionamiento del sistema económico estaría asegurado sin la intervención del estado, dando paso a la expresión Laissez faire et laissez passer, le monde va de lui même; «Dejen hacer, dejen pasar, el mundo va solo».

A pesar que esta propuesta no fue recibida con los brazos abiertos por Adam Smith, sí desempeño un papel importante en el desarrollo de dichas teorías a través de la explicación acerca de la conformación del valor de las mercancías. Adam Smith a través de la teoría del valor-trabajo señaló que la forma en que los bienes adquieren valor se basa en la cantidad de 
trabajo convertido en días de subsistencia, es decir, puede medirse mediante la cantidad de trabajo que lleva incorporado. A esta corriente del pensamiento económico se le identificó como escuela clásica. Posteriormente, David Ricardo a finales de la segunda década del siglo XIX, desarrolló una teoría del valor-trabajo, la cual contiene una crítica acerca del patrón invariable que era el trabajo. La teoría ricardiana menciona que la forma por la que los bienes adquieren valor está dada por la proporción entre las distintas clases de trabajo que se necesitan para adquirirlos, digamos que la única circunstancia que puede servir para el cambio recíproco de diferentes bienes, es la proporción entre distintas clases de trabajo que se incorpora. Por consiguiente, durante esta etapa se consideraba como fuente de valor al coste de producción.

En contraparte a las teorías del valor-trabajo de orientación clásica, a mediados del siglo XIX Carlos Marx analiza el concepto valor y propone la teoría del valor-trabajo. Marx parte de la idea de que el trabajo no es valor por naturaleza, sino, es lo que produce valor. Continúa señalando que el valor de las mercancías no sólo se mide de acuerdo al tiempo de trabajo incorporado en ellas, haciendo referencia al modelo de producción capitalista, sino además, obedece a la estructura social y a las relaciones sociales de producción.

Ante esta realidad, la principal característica de las sociedades capitalistas no es la producción de mercancías o bienes para la satisfacción propia, sino para el intercambio. Por consiguiente, las mercancías adquieren valor de uso y valor de cambio. Estamos hablando de valor de uso cuando el objeto adquiere significación de utilidad (Marx, 1867). Es decir, la utilidad de una cosa, las cualidades que le permiten satisfacer tales o cuales necesidades del hombre, hacen de ella un valor de uso (Academia de Ciencias de la URSS, 1960). Mientras que, estamos hablando de valor de cambio cuando el objeto tiene capacidad para obtener otras mercancías al cambio. El valor de cambio aparece como la relación cuantitativa, como la proporción en que se cambian valores de uso de una clase por valores de uso de otra clase (Marx, 1867).

En ese sentido, el concepto valor se erige como un término ambiguo, con dos concepciones sustantivas: a) transaccional-adquisitivo y, b) psicológico-hedonista. Por un lado sirve para realizar transacciones mercantiles, mientras que por el otro para satisfacer placeres.

En continuidad a la escuela clásica, durante finales del siglo XIX nace la escuela económica neoclásica cuya propuesta acerca de la determinación del valor de los bienes está basada en la 
utilidad que brinda el bien en cuestión. Dentro de la misma escuela del pensamiento neoclásico, Lionel Robbins (1932) economista británico, introdujo el concepto escasez a la definición de economía -150 años aproximadamente después del nacimiento de la ciencia como tal—. En ella señala que "economía es la ciencia que estudia la conducta humana como una relación entre fines y medios limitados que tienen diversa aplicación”.

La escasez es un concepto de carácter relativo, asociado a la necesidad de un bien, es decir, aquellas cosas que son útiles para satisfacer necesidades. El estudio de la escasez se ha abordado desde dos enfoques fundamentales, uno de carácter físico-natural y, otro económico.

a) Físico-natural. El grado de escasez se determina en relación con su disponibilidad física, por la cantidad de elementos existentes en función de algo.

b) Económico. El grado de escasez está asociado a la cantidad existente del bien, y la necesidad y capacidad que posee el bien para satisfacer necesidades.

Como se observa, en ambos enfoques el énfasis está dirigido a la insuficiencia en la cantidad del recurso, donde, la conformación de los precios y la distribución de la renta son resultado del comportamiento entre la oferta y la demanda. Por lo tanto, destaca la estrecha relación con el mercado.

El mercado desde la economía positiva se constituye como lugar, institución y entidad abstracta en la que se enfrentan la oferta y la demanda. INDAABIN lo define como "el entorno en el que se intercambian bienes y servicios entre compradores y vendedores, mediante un mecanismo de precio. En este intercambio, señala, cada parte responde a las relaciones de la oferta y la demanda y, en consecuencia, se determina el valor de mercado.

El valor de mercado, señala García Almirall (2007), "es aquel que presenta una cierta proporcionalidad entre productos similares intercambiables, es decir, que refleja un funcionamiento normal del mercado, y que además mantiene una cierta consistencia en el valor, que no sufre excesivas alteraciones en cortos periodos de tiempo". Para alcanzar el nivel de mercado perfecto, el modelo debe poseer entre otras condiciones: $a$ ) libertad de entrada en el mercado, $b$ ) imposibilidad de influencia en el precio por parte de los vendedores y/o compradores y, c) inexistencia de colusión. 
Ante esta aseveración es importante plantear a manera de contrastación con el contenido de la misma el señalamiento de Foucault (1968) quien menciona que los bienes adquieren valor por el consumo y no por la producción y es en el mercado donde se refleja la relación a través de la demanda y la oferta del bien. Este reflejo, como señala Marshall (1980), corresponde a la acción individual y social que se relaciona más de cerca con la obtención y el empleo de los requisitos materiales del bienestar.

\section{Alcance y retos del proceso valuatorio de inmuebles}

En conclusión podemos establecer que el proceso de la valuación inmobiliaria en México presenta las siguientes limitaciones:

Marco regulatorio. Los servicios de valuación en nuestro país no guardan un paralelismo preciso con las normas valuatorias de orden internacional. Excepto lo que respecta a enfoques y técnicas, las cuales son exclusivas de las estructuras de libre mercado. Por su parte, la regulación mexicana sí guarda una correspondencia ideológica con las normas internacionales, cuyo sustento son los postulados de la economía neoclásica. Esta correlación puede interpretarse como una alineación/acomodo desde $\mathrm{y}$, en lo global, y efecto en la conformación de lineamientos/regulaciones en lo local.

Que los procesos valuatorios y en especial lo que respecta a la valuación inmobiliaria son realizados desde los términos tradicionales establecidos por el marco regulatorio mexicano, sin plantear una nueva manera de valuar, a su vez, sin plantear una manera integral multidisciplinar. Lo que limita el análisis de las implicaciones y la correlación con otros fenómenos.

Que los enfoques establecidos en el marco regulatorio para los servicios de valuación y en especial para la valuación inmobiliaria sólo permiten la utilización del enfoque comparativo o de mercado, el físico o de costos, el de capitalización de rentas y el residual.

Que el valor de mercado de los distintos bienes se determina de acuerdo a la demanda de los mismos, la cual se origina mediante la relación entre la demanda que existe de un bien en el mercado y la cantidad del mismo que es ofrecido. Esta determinación se ve influenciada de manera sustantiva por el grado de escasez que presenta el bien en el mercado en un determinado 
momento. Asimismo, esta escasez se ve originada por la condición psicológica-hedonista que genera en el adquiriente.

Ante este orden de ideas podemos establecer que el actual proceso de valuación inmobiliaria en nuestro país presenta una importante lejanía respecto a la conceptualización del término y, debilidad analítica respecto a fenómenos multidisciplinares que ocurren en la actualidad en el campo del urbanismo, la sociología, el medio ambiente, etc.

\section{Bibliografía}

Aguado, Dolores. (2002). La valoración de bienes inmuebles. Normativa del proceso. España: Dirección General del Catastro. Sitio web: http://www.catastro.meh.es/documentos/publicaciones/ct/ct45/10.pdf. Recuperado 20/04/2015. Álvarez-Buylla, Alicia. (2003). Enfoques valuatorios. Avalúos Inmobiliarios”. En: Taller Técnico del Lincoln Institute of Land Policy. La Habana.

Arechederra, Eva. (2010). Método de valuación de inmuebles históricos. México: Universidad Juárez Autónoma de Tabasco.

Aznar, Jerónimo. (2005).

Azuaje, Adriana. (2013). Determinación de métodos de valoración ambiental: caso Palma de Cera del municipio de Salento, Quindío. Colombia: UGCA.

Congreso del estado de Jalisco. (1998). Ley de valuación del estado de Jalisco. México. Sitio web: http://info.jalisco.gob.mx/sites/default/files/leyes/Ley_Valuacion_Jalisco.pdf. Recuperado: $12 / 02 / 2015$.

Fitch, Jesús. (2011. Valuación de la producción y organización territorial: una modelación hedónica: San Nicolás de los garza, México. Lisboa: Department of Civil Engineering of the University of Coimbra and e-GEO, Research Center in Geography and Regional Planning of the Faculty of Social Sciences and Humanities of the Nova. Sitio web: http://upcommons.upc.edu/revistes/handle/2099/15440. Recuperado: 20/04/2015. 
Foucault, M. (1968). Las palabras y las cosas. Una arqueología de las ciencias humanas. Argentina: Siglo XXI.

Friedman, Milton. (1953). Essays in Positive Economics. Part I. The Methodology of Positive Economics. Chicago: University of Chicago Press.

Funes, Yolanda. (2009). Valuación de los activos intangibles. Caso de la UNAM. México: UNAM. Sitio web: http://www.redalyc.org/articulo.oa?id=34213111003. Recuperado: 10/04/2015.

García, Almirall. (2007). Introducción a la valoración inmobiliaria. Barcelona: UPC.

International Valuation Standards Counsil. (2010). Normas Internacionales de Valoración. Reino Unido: IVSC.Org. Sitio web: http://www.ivsc.org/. Recuperado: 25/04/2015.

Lamothe, Prosper y Pérez, Miguel. (2006). Opciones financieras y productos. España: McgrawHill.

Leguey, Santiago y Llerena, Francese. (1998). Valoración de opciones de compra bermuda con precios de ejercicio variables. Revista Española de Economía, Vol. 15, n 2, 1998. Pp. $199-216$.

Marshall, A. (1890). Principles of economics. Journal of economic literature, 21, junio, 481-517.

Pereyra, Manuel. (2008). Valoración de empresas: una revisión de los métodos actuales. Uruguay: Universidad ORT.

Diccionario de la lengua española. (2012). Diccionarios. España: Real Academia Española. Sitio web: http://www.rae.es/. Recuperado: 01/01/2015 - 25/05/2015.

Robbins, L. (1932). Ensayo sobre la naturaleza y significación de la ciencia económica. Londres: The London School of Economics.

Roca, Josep. (2010). La estructura de las metrópolis contemporáneas. México: Universidad de Guadalajara. Doctorado en Ciudad, Territorio y Sustentabilidad. Sitio web: http://wwwcpsv.upc.es/documents/Ponencia\%20Roca\%20GDL\%202010.pdf. Recuperado: 15/04/2015.

Sánchez, Rafael. (1986). Historia moderna de la valuación en la república mexicana. México: INDAABIN.

Secretaría de Gobernación. (2009a). Procedimiento Técnico PT-RES para la elaboración de trabajos valuatorios que permitan dictaminar el valor de terrenos urbanos y terrenos urbanos con construcción por el método residual. México: Diario Oficial de la Federación. 
Secretaría de Gobernación. (2009b). Metodología y Criterios de Carácter Técnico para la elaboración de trabajos valuatorios que permitan dictaminar el monto de compensación y de indemnización por la expropiación, ocupación temporal o limitación de derechos de dominio sobre bienes inmuebles y nacionalización de unidades económicas por causa de utilidad pública, así como afectación por actos de autoridad y reparación de daños y perjuicios. México: Diario Oficial de la Federación.

Secretaría de Gobernación. (2009c). Metodología y criterios de carácter técnico para la elaboración de trabajos valuatorios que permitan dictaminar el valor de los bienes intangibles, bienes inmuebles, bienes muebles usados, unidades instaladas y unidades económicas de los que las dependencias, la Procuraduría General de la República, las unidades administrativas de la Presidencia de la República y las entidades pretendan adquirir derechos de propiedad, posesión o cualquier otro derecho real mediante compraventa, arrendamiento financiero, permuta, donación y dación en pago. México: Diario Oficial de la Federación.

Secretaría de Gobernación. (2009d). Metodología y criterios de carácter técnico para la elaboración de trabajos valuatorios que permitan dictaminar el valor de los bienes intangibles, bienes inmuebles, bienes muebles, unidades instaladas y unidades económicas que pretendan enajenar las dependencias, la Procuraduría General de la República, las unidades administrativas de la Presidencia de la República, las entidades y en su caso las demás instituciones públicas. México: Diario Oficial de la Federación.

Secretaría de Gobernación. (2004). Ley General de Bienes Nacionales. México: Diario Oficial de la federación.

Secretaría de Hacienda y Crédito Público. (20113). Norma Específica de Información Financiera Gubernamental. NEIFG 003 - Bienes Nacionales. México: SHCP.

Siade, Juan. (2005). Los métodos de valuación de empresas y su relación con la capacidad de las organizaciones para generar valor. Propuesta para reportar en la información financiera el valor de las organizaciones y su capacidad para generarlo. México: UNAM. Sitio web: http://www.ejournal.unam.mx/rca/217/RCA21702.pdf. Recuperado: 20/04/2015. 


\section{Notas}

${ }^{1}$ Avalúo. Es el resultado del proceso de estimar el valor de un bien, determinando la medida de su poder de cambio en unidades monetarias y a una fecha determinada. Es asimismo un dictamen técnico en el que se indica el valor de un bien a partir de sus características físicas, su ubicación, su uso y de una investigación y análisis de mercado. (INDAABIN: http://www.sct.gob.mx/obrapublica/MarcoNormativo/3/3-2/3-214.pdf).

${ }^{2}$ El Instituto de Administración y Avalúos de Bienes Nacionales es un organismo público desconcentrado de la Secretaría de la Función Pública, cuyo objeto es administrar y valuar el patrimonio inmobiliario federal y paraestatal, así como procurar una Administración Pública que cuente con los inmuebles adecuados para el pleno ejercicio administrativo.

${ }^{3}$ La determinación de los valores tendrá tres modalidades generales o específicas: 1) valuación de bienes inmuebles, b) valuación de bienes muebles, y c) valuación de bienes intangibles.

La determinación de los valores, atendiendo a la actividad principal en que se utilicen, tendrán las siguientes modalidades específicas: I. agropecuaria, II. Industrial, III. Actividades extractivas, IV. De habitación con objetivo social o de interés social, V. comercial, VI. Otras modalidades que determine el reglamento de esta ley (Congreso del Estado de Jalisco: 1998).

${ }^{4}$ IVSC es el órgano sucesor del Comité de Normas de Valoración Internacional, que desde la década de 1980 hasta 2007 ha desarrollado y publicado las Normas de Valoración Internacional (IVS). Las IVS establecen un marco para la práctica de la valuación y explican los principios y la terminología para entender la valuación.

5 La Secretaría de Economía, por conducto de la Dirección General de Normas, con fundamento en los artículos 34 fracciones XIII y XXXI de la Ley Orgánica de la Administración Pública Federal; 51-A, 51-B, 54, 66 fracciones III y V de la Ley Federal sobre Metrología y Normalización, 46, 47 del Reglamento de la Ley Federal sobre Metrología y Normalización y 19 fracciones I y XV del Reglamento Interior de esta Secretaría y habiéndose satisfecho el procedimiento previsto por la ley de la materia para estos efectos, expide la declaratoria de vigencia de la norma mexicana que se enlista a continuación, misma que ha sido elaborada, aprobada y publicada como proyecto de norma mexicana bajo la responsabilidad del Comité Técnico de Normalización Nacional en Materia de Información en Prestación de Servicios y del organismo nacional de normalización denominado Organismo Nacional de Normalización y Certificación de la Construcción y Edificación, S.C. (ONNCCE), lo que se hace del conocimiento de los productores, distribuidores, consumidores y del público en general.

${ }^{6}$ SEGOB 2004. Artículo 3.- Son bienes nacionales: 
I. Los señalados en los artículos 27, párrafos cuarto, quinto y octavo; 42, fracción IV, y 132 de la Constitución Política de los Estados Unidos Mexicanos;

II. Los bienes de uso común a que se refiere el artículo 7 de esta Ley;

III. Los bienes muebles e inmuebles de la Federación;

IV. Los bienes muebles e inmuebles propiedad de las entidades;

V. Los bienes muebles e inmuebles propiedad de las instituciones de carácter federal con personalidad jurídica y patrimonio propios a las que la Constitución Política de los Estados Unidos Mexicanos les otorga autonomía,

VI. Los demás bienes considerados por otras leyes como nacionales.

${ }^{7}$ FOVI (antecedente de la Sociedad Hipotecaria Federal) es un Fideicomiso Público constituido en 1963 por el Gobierno Federal a través de la Secretaría de Hacienda y Crédito Público en Banco de México, el cual es administrado por la Sociedad Hipotecaria Federal, S.N.C. a partir del 26 de febrero de 2002.

Dentro de sus fines se encuentra el otorgar apoyos financieros y garantías para la construcción y adquisición de vivienda de interés social, canalizando los recursos a través de los intermediarios financieros, siendo éstos las instituciones de banca múltiple y las Sociedades Financieras de Objeto Limitado (SOFOLES) del ramo hipotecario e inmobiliario, registradas ante FOVI.

Sociedad Hipotecaria Federal, S.N.C., (SHF) es una institución financiera perteneciente a la Banca de Desarrollo, creada en 2001, con el fin de propiciar el acceso a la vivienda de calidad a los mexicanos que la demandan, al establecer las condiciones para que se destinen recursos públicos y privados a la oferta de créditos hipotecarios. Mediante el otorgamiento de créditos y garantías, SHF promueve la construcción y adquisición de viviendas preferentemente de interés social y medio.

${ }^{8}$ Diario Oficial de la Federación. Publicadas el día 4 de octubre de 2012.

Antecedentes:

Diario Oficial de la Federación. Publicadas el día 27 de septiembre de 2004.

Diario Oficial de la Federación. Publicadas el día 25 de abril de 2005.

Diario Oficial de la Federación. Publicadas el día 30 de octubre de 2009.

Diario Oficial de la Federación. Publicadas el día 24 de febrero de 2012.

Requisitos formales. El Avalúo deberá contar con los siguientes requisitos: 
I.Indicar la denominación social de la Unidad de Valuación que lo emita, su logotipo y su clave de inscripción en el registro correspondiente de la sociedad.

II.Elaborarse en formato digital, conforme lo establecen las Reglas de Carácter General Relativas a la Autorización como Valuador Profesional de Inmuebles Objeto de Créditos Garantizados a la Vivienda, o en papel membretado de la Unidad de Valuación que lo emita. En los casos en que se realice el Avalúo en papel se deberán numerar todas las hojas con referencia del total de páginas que compone el Avalúo.

III.Elaborarse conforme a la estructura, conformación y contenido previstos en la regla Vigesimoséptima y a lo dispuesto en las Reglas de Carácter General Relativas a la Autorización como Valuador Profesional de Inmuebles Objeto de Créditos Garantizados a la Vivienda.

IV.En los casos en que se realice el Avalúo en papel éste deberá contar con una síntesis en la que se señale la siguiente información:

1. Clave del Avalúo. Número asignado por la Unidad de Valuación.

2. Fecha del Avalúo. En formato DD/MM/AAAA.

3. Número de registro del conjunto Infonavit (de ser aplicable).

4. Clave del Controlador que certificó el Avalúo. Número asignado por SHF.

5. Clave del Valuador Profesional. Número asignado por SHF.

6. Clave de la entidad que otorga el crédito.

7. Nombre del constructor para el caso de vivienda nueva.

8. Propósito del Avalúo.

9. Tipo de inmueble a valuar.

10. Calle y número.

11. Nombre del conjunto incluyendo Infonavit.

12. Colonia.

9 Bien inmueble. Es un conjunto de derechos, participaciones y beneficios sobre una porción de tierra con sus mejoras y obras permanentes, incluyendo los beneficios que se obtienen por su usufructo. Las principales características de un bien inmueble son su inmovilidad y su tangibilidad. (SEGOB: 2009).

${ }^{10}$ Secretaría de Gobernación, (2007). Norma Mexicana NMX-C-459-SCFI-ONNCCE2007. México: Diario Oficial de la Federación.

11 Dependiendo de la naturaleza del bien materia de valuación, así como de los términos del contrato para el servicio de valuación, el estado del mercado y las características específicas relacionadas, además del uso y propósito del informe de valuación, el valuador debe obtener el valor comercial o conclusivo, resultante de conocer el indicador de valor mediante los siguientes enfoques:

I.Enfoque físico o de costos

II.Enfoque de capitalización o de ingresos 


\section{III.Enfoque comparativo de mercado}

${ }^{12}$ Principios económicos aplicados a la valuación

I.Principio de sustitución

II.Principio de anticipación

III.Principio de mayor y mejor uso

IV.Principio de oferta y demanda

13 Avalúo Paramétrico es el dictamen valuatorio que emite el INDAABIN para bienes inmuebles,; acorde todo ello a los datos que los usuarios de dependencias, entidades y otras instituciones públicas federales capturen en el módulo de paramétricos del sistema de captura al que les da acceso este instituto una vez que se suscriben al programa... (SHCP: 2013).

${ }^{14}$ El Residual estático

Se identifica como residual estático al análisis que considera la reparación, conclusión de las obras y la operación de compraventa del inmueble analizado.

Este análisis no toma en cuenta el valor del dinero en el tiempo y por tanto calcula el valor residual que puede asignarse a un terreno o terreno con construcciones a partir de la simple diferencia de los ingresos y egresos que el inmueble analizado genera en un momento dado.

Fórmula de cálculo del valor residual por el método estático

El valor residual por el procedimiento estático del objeto de valuación se calculará aplicando la siguiente fórmula:

$$
\mathrm{F}=\mathrm{VM}-\Sigma \mathrm{C} i-\mathrm{b}
$$

En donde:

$\mathrm{F}=$ Valor del terreno o inmueble analizado.

VM $=$ Valor del inmueble en la hipótesis de producto terminado por vender

$\mathrm{b}=$ Beneficio neto del promotor .

$\mathrm{Ci}=$ Cada uno de los costos y gastos necesarios considerados

Dado lo anterior, los conceptos que se incluirán en el análisis deben estimarse sin considerar la temporalidad de los mismos. 
${ }^{15}$ El Residual dinámico

Se identifica como residual dinámico al análisis que considera la operación de compraventa o renta en un plazo cuantificable del inmueble analizado.

En este análisis se toma en cuenta el valor del dinero en el tiempo y por tanto calcula el valor residual que puede asignarse a un terreno o terreno con construcciones a partir del valor presente neto de los flujos de efectivo que el inmueble analizado generará en el futuro.

Dado lo anterior, los conceptos que se incluirán en el análisis deben estimarse tomando en cuenta el momento de su ocurrencia.

Fórmula de cálculo del valor residual por el método dinámico.

El valor residual del inmueble objeto calculado por el procedimiento dinámico será la diferencia entre el valor actual de los cobros obtenidos por la venta o renta del inmueble terminado y el valor actual de los pagos realizados por los diversos costos y gastos, con una tasa de descuento determinada, utilizando la siguiente fórmula:

$$
F=\Sigma\left[\left(C_{j}-P_{j}\right)^{t} /(1+i)^{t i}\right]
$$

En donde:

$\mathrm{F}=$ Valor del terreno o inmueble a rehabilitar.

$\mathrm{Cj}=$ Importe de los cobros previstos en el momento $\mathrm{J}$.

$\mathrm{Pj}=$ Importe de los pagos previstos en el momento $\mathrm{J}$.

tj = Número de periodos de tiempo previsto desde el momento de la valuación hasta que se produce cada uno de los cobros o pagos.

$\mathrm{i}=$ Tasa de descuento.

NEIFG 003 Bienes Nacionales 2011 